\title{
Performance of Zn Electrode in Aqueous Electrolyte Containing Carboxylate
}

\author{
Jinqing Kan \\ School of Chemistry and Chemical Engineering, Yangzhou University \\ Yangzhou, 225002, China \\ jqkan@yzu.edu.cn
}

\section{Extended Abstract}

Zinc is widely used as negative electrode material for the battery due to its excellent electrochemical properties[1-2]. It is hindered that zinc is used in weak acidic electrolyte (for example, aqueous Zn-polyaniline battery[3-6]) because zinc is prone to corrosion and the formation of zinc dendrite cause short circuit of the battery, which lead to reduce battery capacity and shorten the cycle life.

In this paper the influences of carboxylates (sodium formate, sodium acetate, sodium propionate, sodium butyrate, sodium valerate, disodium malonate, disodium succinate) as the additives of aqueous electrolyte on the performance of the $\mathrm{Zn}$ electrode are studied. The results show that the new electrolyte can effectively eliminate the hydrogen evolution corrosion of the zinc electrode and improve the discharge capacity and cycle life of Zn/PANI secondary battery. In the aqueous electrolyte containing $0.2 \mathrm{M}$ disodium malonate the initial discharge specific capacity of the polyaniline in the $\mathrm{Zn}$-polyaniline battery is as high as $131.1 \mathrm{mAh} \mathrm{g}^{-1}$, which is still $110 \mathrm{mAh} \mathrm{g}^{-1}$ and the coulombic efficiency is over $92 \%$ after 100 cycles at a charge/discharge current density of $1 \mathrm{~A} \mathrm{~g}^{-1}$ in the voltage range $1.5 \sim 0.7 \mathrm{~V}$.

Keywords: Zinc, Carboxylate, Polyaniline, Weak Acidic Electrolyte, Hydrogen Evolution Corrosion.

\section{Acknowledgements}

This project was supported by the National Science Foundation of China (No.20873119), and by the Priority Academic Program Development of Jiangsu Higher Education Institutions. Part of the data was from the Testing Center of Yangzhou University.

\section{References}

[1] J. Ollig, V. Kloubert, I. Weßels, H. Haase and L. Rink, "Parameters Influencing Zinc in Experimental Systems in Vivo and in Vitro," Metals, vol. 6, no. 3, p. 71, 2015.

[2] S. Lee, O. Kwon, K. Yoo and R. D. Alorro, "Removal of $\mathrm{Zn}$ from Contaminated Sediment by $\mathrm{FeCl}_{3}$ in $\mathrm{HCl}_{\mathrm{Solution}}$," Metals, vol. 5, no. 4, pp. 1812-1820, 2015.

[3] C. Chen, X. Hong, A. Chen, T. Xu, L. Lu, S. Lin, Y. Gao, "Electrochemical properties of poly (aniline-co-Nmethylthionine) for zinc-conducting polymer rechargeable batteries," Electrochim. Acta, vol. 190, pp. 240-247, 2016.

[4] L. Liu, F. Tian, M. Zhou, H. Guo and X. Wang, "Aqueous rechargeable lithium battery based on polyaniline and $\mathrm{LiMn}_{2} \mathrm{O}_{4}$ with good cycling performance," Electrochim. Acta, vol. 70, pp. 360-364, 2012.

[5] W. Mak, G. Wee, V. Aravindan, N. Gupta, S. Mhaisalkar and S. Madhavi, "High-energy density asymmetric supercapacitor based on electrospun vanadium pentoxide and polyaniline nanofibers in aqueous electrolyte," $J$. Electrochem. Soc., vol. 159, no. 9, pp. A1481-A1488, 2012.

[6] B. C. Dalui, I. N. Basumallick and S. Ghosh, "Zinc-poly (aniline) rechargeable battery assembled with aqueous electrolyte," Indian J. Chem. Techn. vol. 15, no. 6, pp. 576-580, 2008. 